\title{
Genetic diversity of Leishmania donovani that causes cutaneous leishmaniasis in Sri Lanka: a cross sectional study with regional comparisons
}

Udeshika Lakmini Kariyawasam¹, Angamuthu Selvapandiyan², Keshav Rai ${ }^{3}$, Tasaduq Hussain Wani², Kavita Ahuja², Mizra Adil Beg ${ }^{2}$, Hasitha Upendra Premathilake ${ }^{4}$, Narayan Raj Bhattarai ${ }^{3}$, Yamuna Deepani Siriwardena',

Daibin Zhong ${ }^{5}$, Guofa Zhou ${ }^{5}$, Suman Rijal ${ }^{3}$, Hira Nakhasi ${ }^{6}$ and Nadira D. Karunaweera ${ }^{{ }^{*}}$ (D)

\begin{abstract}
Background: Leishmania donovani is the etiological agent of visceral leishmaniasis $(\mathrm{VL})$ in the Indian subcontinent. However, it is also known to cause cutaneous leishmaniasis (CL) in Sri Lanka. Sri Lankan L. donovani differs from other $L$. donovani strains, both at the molecular and biochemical level. To investigate the different species or strain-specific differences of $L$. donovani in Sri Lanka we evaluated sequence variation of the kinetoplastid DNA (kDNA).
\end{abstract}

Methods: Parasites isolated from skin lesions of $34 \mathrm{CL}$ patients and bone marrow aspirates from $4 \mathrm{VL}$ patients were genotyped using the kDNA minicircle PCR analysis. A total of 301 minicircle sequences that included sequences from Sri Lanka, India, Nepal and six reference species of Leishmania were analyzed.

Results: Haplotype diversity of Sri Lankan isolates were high $\left(H_{d}=0.757\right)$ with strong inter-geographical genetic differentiation $\left(F_{S T}>0.25\right)$. In this study, L. donovani isolates clustered according to their geographic origin, while Sri Lankan isolates formed a separate cluster and were clearly distinct from other Leishmania species. Within the Sri Lankan group, there were three distinct sub-clusters formed, from $\mathrm{CL}$ patients who responded to standard antimony therapy, $\mathrm{CL}$ patients who responded poorly to antimony therapy and from $V L$ patients. There was no specific clustering of sequences based on geographical origin within Sri Lanka.

Conclusion: This study reveals high levels of haplotype diversity of L. donovani in Sri Lanka with a distinct genetic association with clinically relevant phenotypic characteristics. The use of genetic tools to identify clinically relevant features of Leishmania parasites has important therapeutic implications for leishmaniasis.

Keywords: Skin lesions, Antimony resistance, Visceral leishmaniasis, kDNA minicircle sequences, Haplotype diversity, Geographical clustering, Phenotypic characteristics, Nepal, India

\footnotetext{
*Correspondence: nadira@parasit.cmb.ac.lk; nkarunaw@hsph.harvard.edu

'Department of Parasitology, Faculty of Medicine, University of Colombo, No.

25, Kynsey Road, Colombo 8, Sri Lanka

Full list of author information is available at the end of the article
} 


\section{Background}

Leishmaniases, caused by the Leishmania species, are a group of vector-borne parasitic diseases with a high disease burden in the Indian sub-continent $[1,2]$. The main clinical forms are cutaneous leishmaniasis (CL), muco-cutaneous leishmaniasis (MCL) and visceral leishmaniasis (VL), which are caused by different species and subspecies of Leishmania [1,3]. Leishmania donovani is widely recognized to cause VL in the old world; while in the new world VL is caused by a closely related species, L. infantum [3-6]. The causative agent of CL in Sri Lanka is $L$. donovani zymodeme MON-37 [7, 8], which is closely related to the common VL causing zymodeme MON-2 in India [9].

$\mathrm{CL}$ is now considered as an endemic disease in Sri Lanka, with a steady increase in the number of cases detected [10, 11]. Since 2001, more than 6500 cases of CL [12] have been reported along with a few MCL and VL cases [13-15]. The steady increase of CL in Sri Lanka is complicated by the appearance and spread of CL that does not respond to the standard antimonial drugs routinely used in clinical practice [16]. Initial studies in Sri Lanka have indicated that both CL and VL are caused by L. donovani- MON-37 [7, 15]. However, the existence and contribution of intra-species variation that influences the clinical manifestations of leishmaniasis and the treatment response to antimonial drugs in Sri Lanka is unknown.

Leishmania donovani virulence factors involved in pathogenesis, visceral organ invasion and parasite persistence, have been extensively studied over several decades [17-19]. The A2 protein production [18, 20, 21], lipophosphoglycan (LPG) activity [22-24], glycoprotein 63 (gP63) gene expression [25, 26], acid phosphatase activity $[18,27]$ and variations in the mini-exon genes of chromosome 36 [17] are known factors that influence the virulence of Leishmania parasites. Further analysis of Sri Lankan L. donovani isolates is thus warranted in order to gain a better understanding of differences in virulence and pathogenicity.

The genetic characterization of Leishmania parasites can be achieved via the analysis of several genetic markers such as mini-exons, microsatellites, ribosomal internal transcribed spacer (ITS) regions and minicircles of kinetoplast DNA [28-31]. The kinetoplast DNA (kDNA) network in Leishmania is composed of two types of DNA rings; maxicircles and minicircles. The Leishmania parasite minicircle kDNA is approximately $1 \mathrm{~kb}$ in size, containing a conserved region that is $\sim 200$ bp in length and a variable region of 600 bp. Leishmania minicircle kDNA provides an ideal target for the genotyping of Leishmania parasite as the sequence differences allow for accurate discrimination between species [32-34].
Previous studies using the minicircle kDNA footprint assay have enabled rapid identification of known or unknown species with a high level of sensitivity [35]. This method is considered to be better suited as compared to other frequently used speciation methods, such as Restriction Fragment Length Polymorphism (RFLP) and Southern blot which depend on low-copy PCR targets (non-minicircle DNA regions) and have limitations in Leishmania with regard to species identification [35-37].

The aim of this study was to use the kDNA footprint assay to study L. donovani strain specific sequence diversity and determine the association between sequence variations and distinct clinical characteristics in individuals with leishmaniasis in Sri Lanka.

\section{Methods}

\section{Study setting and study population}

Sri Lanka

A cross-sectional study of confirmed clinical cases was carried out to represent all the administrative provinces of Sri Lanka over a one year period (Fig. 1). Study participants who were laboratory-confirmed as either CL $(n=34)$ or VL $(n=4)$ were selected. Patients with other skin diseases and who were negative for laboratory diagnosis were excluded. Within the CL group, there were six patients $(n=6)$, who had a history of poor response to the routine local treatment of intra-lesional sodium stibogluconate (IL-SSG). A patient was considered a 'poor responder', if the lesion size (ulceration area in the cases of ulcerative lesions or the induration area in the cases of non-ulcerative lesions) did not decreased by a minimum of $50 \%$ of the pre-treatment size, as judged by the collaborating dermatologists, following a minimum of 10 IL-SSG injections given at weekly intervals, similar to previously described criteria [38-40].

\section{Nepal and India}

Parasite DNA extracts collected via archived samples of L. donovani parasites (from skin lesions of post kala-azar dermal leishmaniasis (PKDL) patients and bone marrow of VL patients) maintained at collaborative centers in India $(n=27)$ and Nepal $(n=26)$, were used for comparative experiments. The kDNA sequences from clinical isolates stored in public databases (GenBank) were also included in the analyses.

\section{Laboratory confirmation of leishmaniasis}

Prior to inclusion in the study, diagnosis of infection was confirmed in all study subjects by the demonstration of Leishmania parasites by oil immersion (X1000) microscopy of Giemsa-stained smears of lesion aspirates or slitskin scrapings of CL patients and bone marrow aspirates of VL patients, either directly or following in-vitro culture. Parasites were grown in M199 medium (Gibco, Invitrogen, USA) supplemented with $15 \%$ heat inactivated fetal 


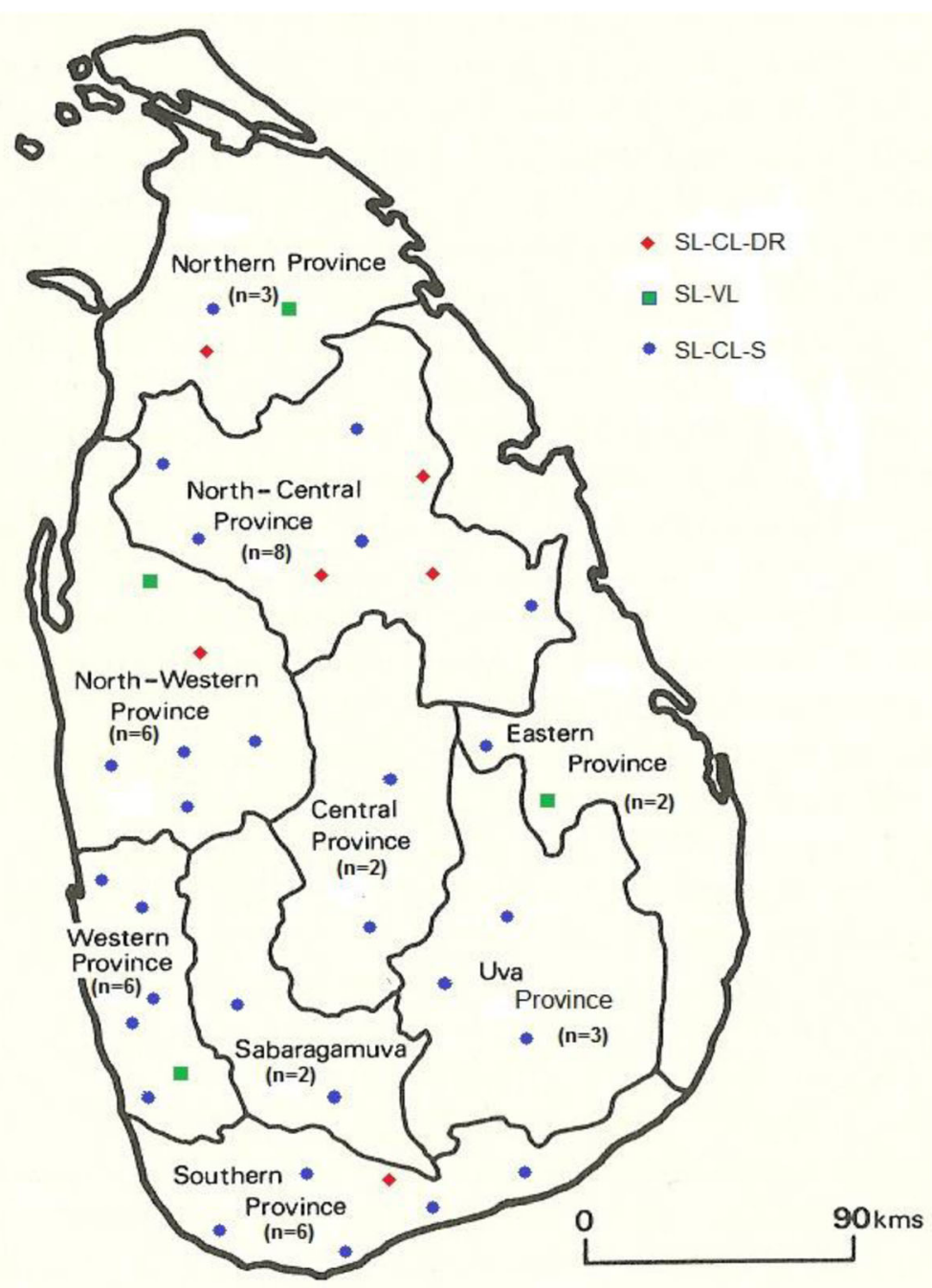

Fig. 1 Geographical distribution of leishmaniasis patients in Sri Lanka included in the study. The geographical origin of leishmaniasis patients within the main administrative provinces of the country are shown with the number of patients from each province given within parenthesis. SL-CL-S: patients with uncomplicated cutaneous leishmaniasis, $\$$ SL-CL-DR: patients with cutaneous leishmaniasis that showed poor response to antimony therapy and $\mathbf{m} \mathrm{SL}-\mathrm{VL}$ : visceral leishmaniasis patients

bovine serum (FBS) (Gibco, Invitrogen, USA) with Penicillin-Streptomycin (Sigma-Aldrich, USA) and the cultures were maintained at $26^{\circ} \mathrm{C}$. Cultured parasites were used for DNA extraction with the use of QIAamp DNA minikit (Qiagen, USA). Laboratory-confirmed patients were referred to the local dermatologist (for CL) and/or consultant physicians (for VL) for treatment according to Sri Lankan Ministry of Health guidelines. IL-SSG poorresponders in the CL group were those re-referred to the department for repeat investigations due to delay or absence of clinical cure.

\section{DNA preparation and sequencing}

Extracted DNA was subjected to a fluorescence-based PCR followed by cloning and sequencing of the resulting DNA fragment according to established protocols [34]. The PCR reaction for kDNA amplification was performed using primers from conserved regions across kinetoplast minicircles of Leishmania spp. (primer JW11-5'CCTATTTTACACCAACCCCCAGT3' and primer JW12-5'GGGTAG GGGCGTTCTGCGAAA3') which generate an approximately 120 bp amplicon [34, 41-43]. Subsequently the amplified products were ligated in the pGEM-T vector and the resulting ligation products were transformed in to $E$. coli TOP 10 competent cells and plated for blue/white screening on plates containing ampicillin $(100 \mu \mathrm{g} / \mathrm{ml}), \mathrm{X}$ gal $(20 \mathrm{mg} / \mathrm{ml})$ and iso-propyl-thio-galactoside $(10 \mu \mathrm{l} / \mathrm{ml}$ of $100 \mathrm{mM})$. The resulting white colonies indicated transformed cells and blue colonies represented nontransformed ones. Individual white transformed colonies were used for plasmid DNA preparation followed by restriction digestion of $1 \mu \mathrm{g}$ of plasmids using EcoRI enzyme 
Table 1 Genetic diversity parameters of Leishmania donovani isolates from Sri Lanka, India and Nepal

\begin{tabular}{llll}
\hline Origin & Sri Lanka & India & Nepal \\
\hline Haplotype diversity $\left(H_{d}\right)$ & 0.757 & 0.889 & 0.725 \\
Nucleotide diversity $\left(N_{d}\right)$ & 0.034 & 0.093 & 0.128 \\
Number of sequences used $(\mathrm{n})$ & 166 & 51 & 52 \\
Number of polymorphic sites $(S)$ & 33 & 36 & 34 \\
Number of Haplotypes $(\mathrm{h})$ & 43 & 8 & 5 \\
Tajima's $D(P$-value) & $-1.098(>0.1)$ & $1.197(>0.1)$ & $2.646(<0.01)$ \\
Fu's Fs tests $(P$-value) & $-25.801(>0.02)$ & $10.780(<0.02)$ & $21.900(<0.02)$ \\
\hline
\end{tabular}

Fu's Fs: Not significant, $P>0.02$. Tajima's D: Not significant, $P>0.10$

at $37^{\circ} \mathrm{C}$ (Promega, USA), according to the manufacturer's recommendations. The total reaction volume was subjected to electrophoresis, in $2 \%$ agarose gel to confirm the presence of an insert. The inserts from the individual clones were sequenced with M13 forward primer.

\section{Genetic analysis}

Minicircle sequence analysis of parasite isolates

A total of $301 \mathrm{~L}$. donovani sequences of parasite isolates from Sri Lanka $(n=38)$, India $(n=27)$ and Nepal $(n=26)$ were analyzed, along with minicircle sequences of 6 Leishmania reference species from different countries [34]. Multiple sequence alignment (MSA) was done, via CLUSTAL-X MSA Program, version 2.0, with a gap opening penalty of 10.00; gap extension penalty of 0.05 ; DNA transition weight of $0.50[44,45]$. The DnaSP software was utilized to measure haplotype diversity $\left(H_{d}\right)$, Nucleotide diversity $\left(N_{\mathrm{d}}\right)$ and pair wise fixation index $\left(F_{S T}\right)$ for each group [46]. Furthermore, Tajima's $D$ Test [47] and Fu's Fs test [48] were also performed for detection of population growth (neutrality test for selection). The Haplotype diversity is defined as $H_{d}=[n /(\mathrm{n}-1)]\left[1-\Sigma P_{i}^{2}\right]$, with $n$ being the number of sequences analyzed and $p_{i}$ is the relative frequency of haplotype $i$. The nucleotide diversity is defined as, $N_{d}=[n /(\mathrm{n}-1)]\left[1-\sum x_{i j}^{2}\right]$, where $x_{i j}$ is the relative frequency of nucleotide variant $j(j=1,2,3$ and 4 correspond to A, C, G and T) at site $i . H_{d}>0.5$ and $N_{d}>0.1$ reflect high haplotype and nucleotide diversity, respectively within the study population $[46,49]$.

Tajima's D Test is a measure of selection through the patterns of genetic diversity within populations, whether they are consistent with neutral expectations. Positive D

Table 2 kDNA based genetic distances $\left(F_{S T}\right)$ between populations of Leishmania parasites from selected geographical areas

\begin{tabular}{llll}
\hline & Sri Lanka & India & Nepal \\
\hline Sri Lanka & 0.000 & & \\
India & 0.347 & 0.000 & \\
Nepal & $0.522^{a}$ & 0.236 & 0.000 \\
\hline
\end{tabular}

${ }^{\mathrm{a}}$ Significant at level of 0.05

Diagonal: genetic distance within major geographic areas; below diagonal: genetic distance between populations value suggests a recent population bottleneck or balancing selection, while negative $\mathrm{D}$ value suggests population expansion or purifying selection [50]. Fu's Fs test is another measure of selection, which is based on the infinite sites model of mutation, and tests the number of alleles in a population and indicates whether they are consistent with neutral expectations. Fu's statistic is thought to be a more sensitive indicator of population expansion and genetic hitchhiking than Tajimas D. $F_{S T}$ measures genetic differentiation among subpopulations. According to established standards, $F_{S T}$ values from 0.0 0.05 indicate little genetic differentiation, whereas values that range from $0.05-0.15,0.15-0.25$ and $>0.25$ are considered to be representing moderate, great and strong genetic differentiation, respectively $[51,52]$. The 'isolation by distance analysis' was performed using IBDWS [53]. Three populations were defined for this analysis viz., Sri Lanka, India and Nepal.

\section{Phylogenetic analysis}

Phylogenetic analysis was done using all sequences $(n=$ 301) generated as described above. Previously published minicircle sequences of $L$. donovani (DD8), $L$. infantum (TK), L.infantum (SP), L. major (Al), L. braziliensis (P), L.tropica (TK) and L. amazonensis from the minicircle sequence database of GenBank, were also used in the phylogenetic analysis as reference sequences. The phylogenetic trees were constructed using the neighbor joining method, implemented in MEGA7.0.7 [54]. The evolutionary distances were computed using the Maximum Composite Likelihood method and depicted in units of number of base substitutions per site [54-56]. The tree was drawn to scale, with branch lengths in the same units as those of the evolutionary distances used to infer the phylogenetic tree. The resulting Guide Trees, showed cluster relationships among the sequences and allowed the assignment of test sequences to one of the reference species.

\section{Results}

PCR amplification of Leishmania kDNA sequence segments from Sri Lanka showed a single approximately 120bp band on $2 \%$ agarose gel, which was consistent with the 


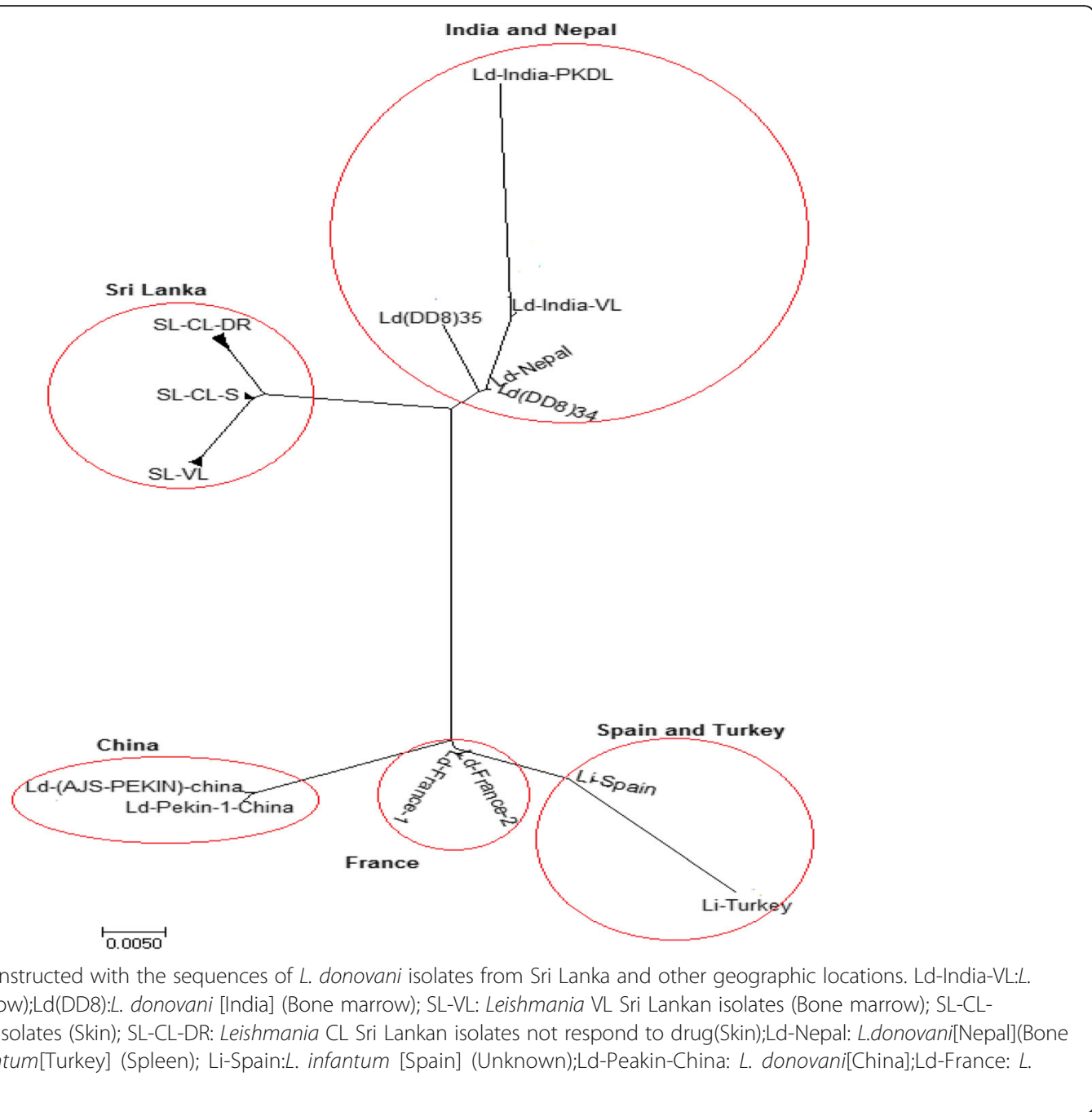

product size of $L$. donovani as shown previously [34]. The multiple sequence alignment clearly showed a high level of genetic variation within the variable regions, whereas the conserved regions showed $83 \%$ nucleotide identity on average, in all sequences (Additional file 1).

The genetic diversity among Sri Lankan sequences was high, evidenced by the high haplotype diversity $\left(H_{d}=\right.$ $0.757)$ and high nucleotide diversity $\left(N_{d}=0.03\right)$ that were, comparable to the values of other tested $L$. donovani sequences from the Indian subcontinent (Table 1). Out of the $H_{d}$ values generated for the Indian subcontinent, the highest value $\left(H_{d}=0.889\right)$ was observed for the Indian parasite sequences, with similar trends seen with nucleotide diversity $\left(N_{d}=0.093\right)$ (Table 1$)$. Negative values were observed for both Fu's Fs test (-25.801) and Tajima's D test $(-1.098)$ for Sri Lankan sequences only (Table 1$)$. In contrast, positive Fu's Fs test and Tajima's D values were observed for sequences from India and Nepal.

Inter geographical genetic differentiation $\left(F_{S T}\right)$ of Leishmania parasite populations from Sri Lanka, India and Nepal is depicted in Table 2. There was significant $(P<0.05)$ genetic differentiation of Sri Lankan Leishmania sequences when compared with those that originated from other countries included in the analysis (Table 2). Significantly high levels of genetic differentiation $\left(F_{\mathrm{ST}}>0.25\right)$ was observed between Sri Lankan sequences and those from India and Nepal, while there was moderate levels of differentiation $(<0.25)$ between Indian sequences and those from Nepal (Table 2). The isolation by distance analysis showed a linear correlation between genetic diversity and geographic distance, which might demonstrate the effects of gene flow or genetic barrier among parasite populations (Additional file 2). However, this correlation was not statistically significant.

In the phylogenetic analysis, all Leishmania sequences from Sri Lanka appeared to form a uniquely distinguishable group and were clearly distinct from other new and old world cutaneous leishmaniasis species found elsewhere (Figs. 2 and 3a). However, the Sri Lankan minicircle sequences were better linked in a grouping with 


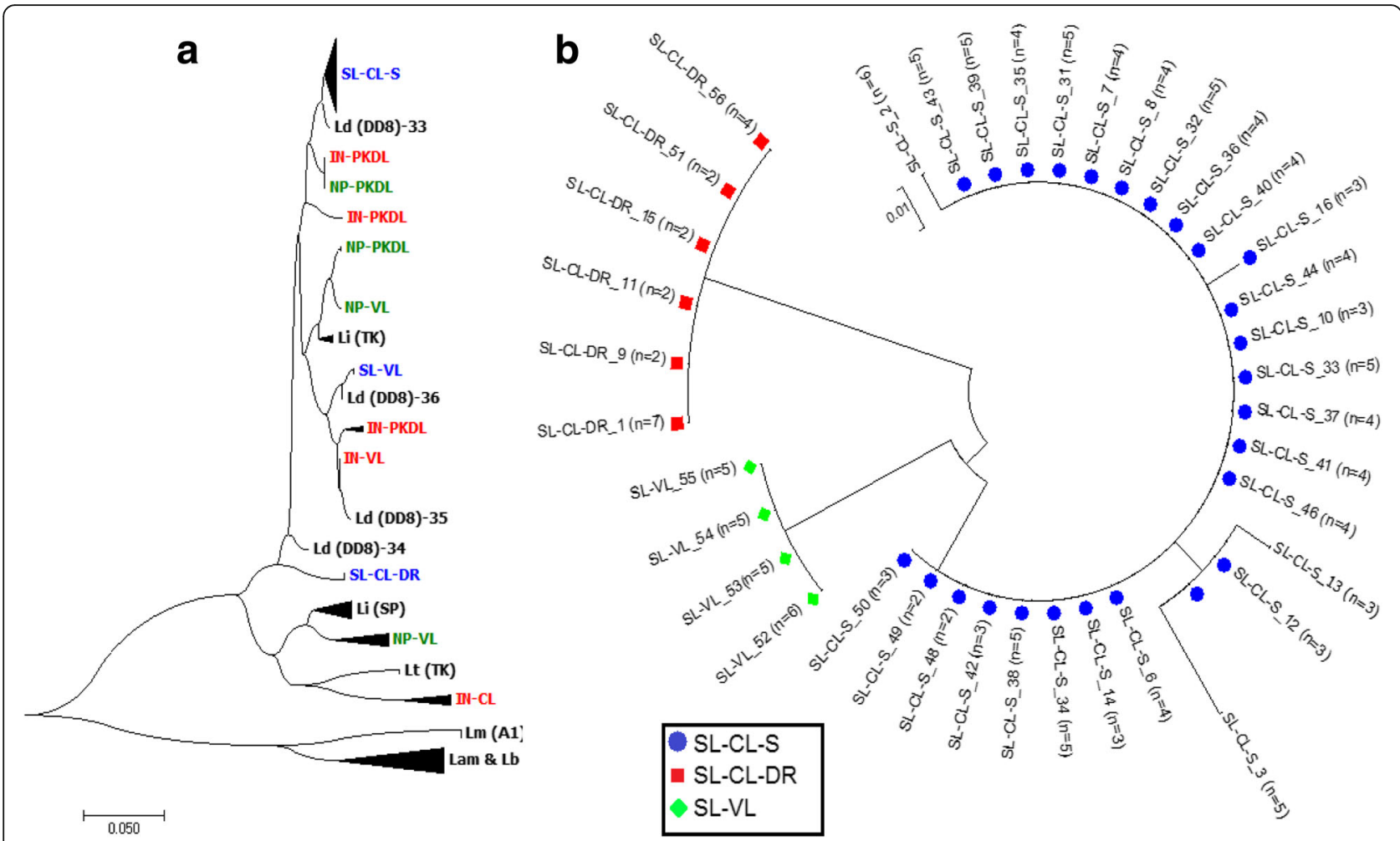

Fig. 3 Phylogenetic trees with the Leishmania strains from Sri Lanka (SL), India (IN) and Nepal (NP) with (a) and / without (b) the global Leishmania reference panel consisting of different species of Leishmania from different regions. Lb(P):L. braziliensis [Peru] (Skin);Ld(DD8)/Ld(IN):L. donovani [India] (Bone marrow); Li(SP):L. infantum [Spain] (Unknown); Lm(A1):L. major [Libya]; Lt(TK):L. tropica [Turkey] (Skin); Lam: L. amazonenis (Skin); Li(TK):L. infantum [Turkey] (Spleen); SL-VL (52-55): VL Sri Lankan isolate (Bone marrow); SL_CL-S (2,3,6-8,10-14,16,17,31-46,48-50):Leishmania CL Sri Lankan isolate (Skin); SL_CL-DR (1,9,11,15,51,56):Leishmania CL Sri Lankan that failed to respond to antimonial drugs (Skin); IN-VL: L. donovani [India] (Bone marrow); IN-PKDL: Leishmania from post-kala azar dermal leishmaniasis (PKDL) [India] (Skin); NP-VL: Leishmania VL Nepalian isolate (Bone marrow); NP-PKDL:Leishmania cause PKDL [Nepal] (Skin)

other visceralizing Leishmania parasites, rather than the dermotropic species (Fig. 3a). Furthermore, the sequences from Sri Lanka, India and Nepal formed sister clusters when analyzed with other Leishmania sequences from the global reference panel (Fig. 3a). All the sequences from Sri Lanka were grouped alongside L. donovani (Fig. 3a). Within the Sri Lankan group, clear clustering was apparent among parasites that belonged to different clinical groups, which included uncomplicated cutaneous leishmaniasis (SL-CL-S), cutaneous leishmaniasis that showed poor response to antimony therapy (SL-CL-DR) and visceral disease (SL-VL) (Fig. 3a and b).

Similar analyses were conducted for the isolates from India and Nepal. The sequences of the Indian and Nepalese parasites causing VL and post kala-azar dermal leishmaniasis (PKDL), clustered within the VL group of the reference panel positioned closer to $L$. donovani and L. infantum (Figs. 3a, 4a and 5a), while CL causing parasites obtained from skin lesions of Indian patients, formed a sister cluster with L. tropica (Fig. 4). However, there were no distinct subgroups within $L$. donovani that induce either VL or PKDL either in India or Nepal (Fig. 3a). This lack of clustering was further confirmed via internal comparison of Indian and Nepalese sequences (Figs. 4 and 5). None of the Sri Lankan, Indian or Nepalese isolates clustered with $L$. major, $L$. braziliensis or $L$. amazonensis (Figs. 3a, 4a and 5a).

\section{Discussion}

This study was aimed to examine genetic diversity, population structure, phylogenetic relationships as well as the association between genotypic and phenotypic characteristics of L. donovani in Sri Lanka with the use of a minicircle-based strain specific sequence diversity assay. Attempts were also made to investigate Sri Lankan $L$. donovani sequences in relation to those in the neighboring countries of India and Nepal as well as the rest of the world. Distinct genetic clustering of Sri Lankan parasites according to their phenotypic properties, coupled with an admixed nature of the population was observed for the first time in Sri Lanka.

In the multiple sequence alignment, unique conserved regions could be clearly identified with minor gaps and 


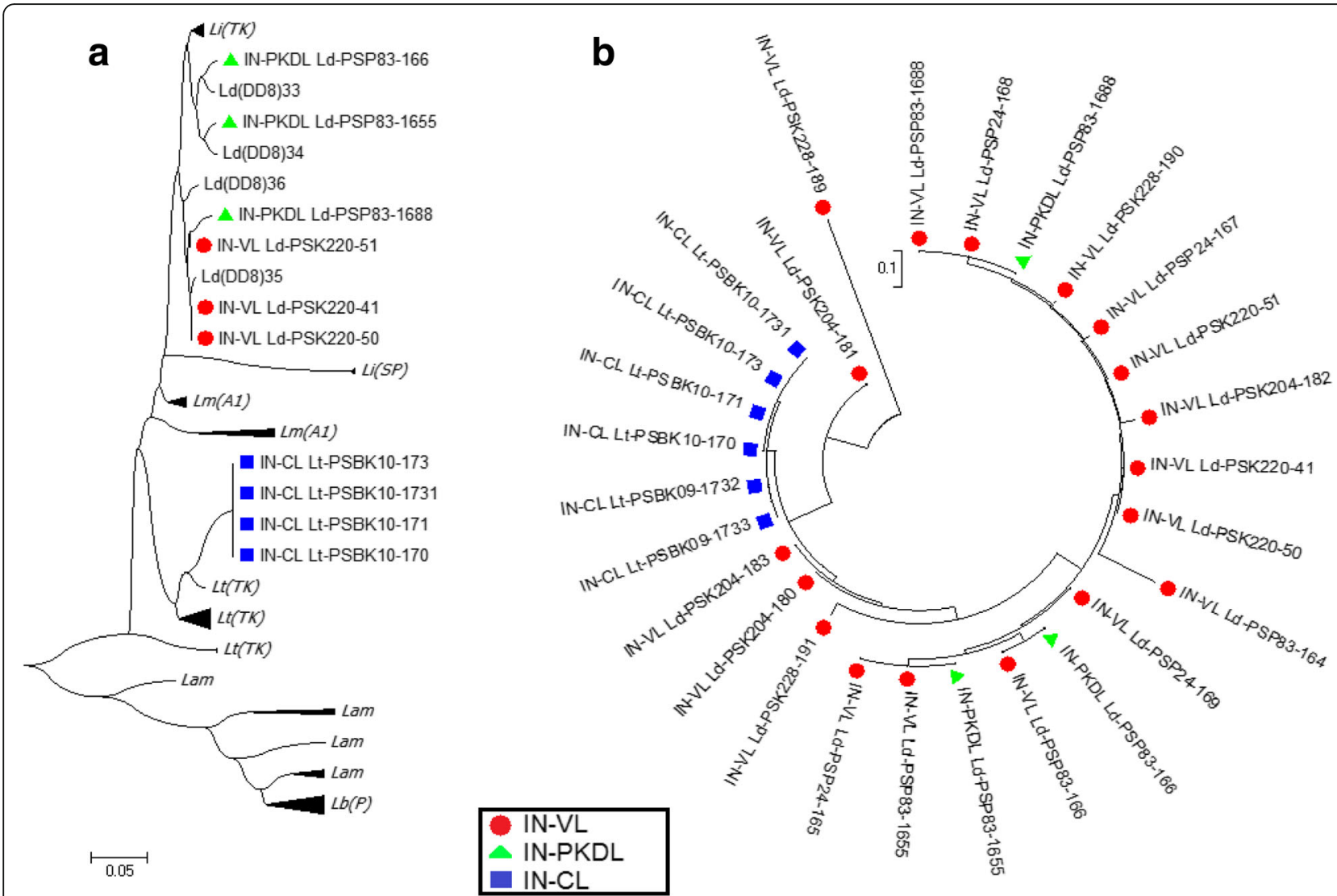

Fig. 4 Phylogenetic trees constructed with the sequences of Indian parasite isolates. a Phylogenetic tree constructed with the sequences of parasite isolates with the global reference panel. b Phylogenetic tree constructed for internal comparison of the sequences of parasite isolates. Lb(P):L. braziliensis [Peru] (Skin); Ld(DD8)/Ld(IN): L. donovani [India] (Bone marrow); Li(SP):L. infantum [Spain] (Unknown); Lm(A1):L. major [Libya]; Lt(TK):L. tropica [Turkey] (Skin); Lam: L. amazonenis (Skin); Li(TK):L. infantum [Turkey] (Spleen), IN-VL; L. donovani [India] (Bone marrow), IN-PKDL; Leishmania from PKDL [India] (Skin)

nucleotide mismatches, since such regions remain conserved across many species and between classes of the same species. The existence of minicircle sequence haplotype diversity among different species and within the same species of Leishmania is fairly well established [41, 57-61]. The haplotype diversity value based on minicircle sequences revealed the degree of diversity within the Sri Lankan isolates with different phenotypic properties. Furthermore, lack of clear genotypic pattern in relation to geography within the country was revealed, indicating a population mix or presence of gene flow between parasite populations that may be still in the process of expansion. High levels of haplotype and nucleotide diversity were observed in Sri Lankan, Nepalese and Indian sequences. However, the highest haplotype diversity and nucleotide diversity were observed for the Indian parasite sequences indicating the highly diverse nature of the Indian isolates when compared to the Sri Lankan and Nepalese counterparts.

Indeed, a recent population expansion or an existence of an excess number of alleles often observed in genetic hitch-hiking was evident from Fu's Fs test for Sri Lankan sequences, where a negative Tajima's D test implies purifying selection. In contrast, positive $F$ s value observed in both Nepal and Indian sequences are an indication of deficient alleles, suggestive of a recent population bottleneck, and a positive Tajima's D points towards a balancing selection.

The degree of variability within Leishmania species has been linked to the number of vectors and/or animal reservoir(s) involved in the transmission of these parasites [62,63]. Therefore, the high variability found in Leishmania isolates in Sri Lanka, could be due to its transmission associated with several sub-populations of sand flies that belong to the genus Phlebotomus reported from various parts of Sri Lanka [64, 65].

This study confirms that, sequences of the Sri Lankan, Indian and Nepalese (VL and PKDL) parasites, clustered within the L. donovani complex, while CL causing parasites obtained from skin lesions of Indian patients, formed a sister cluster with $L$. tropica. None of the Sri Lankan CL and VL parasites were found to be associated 


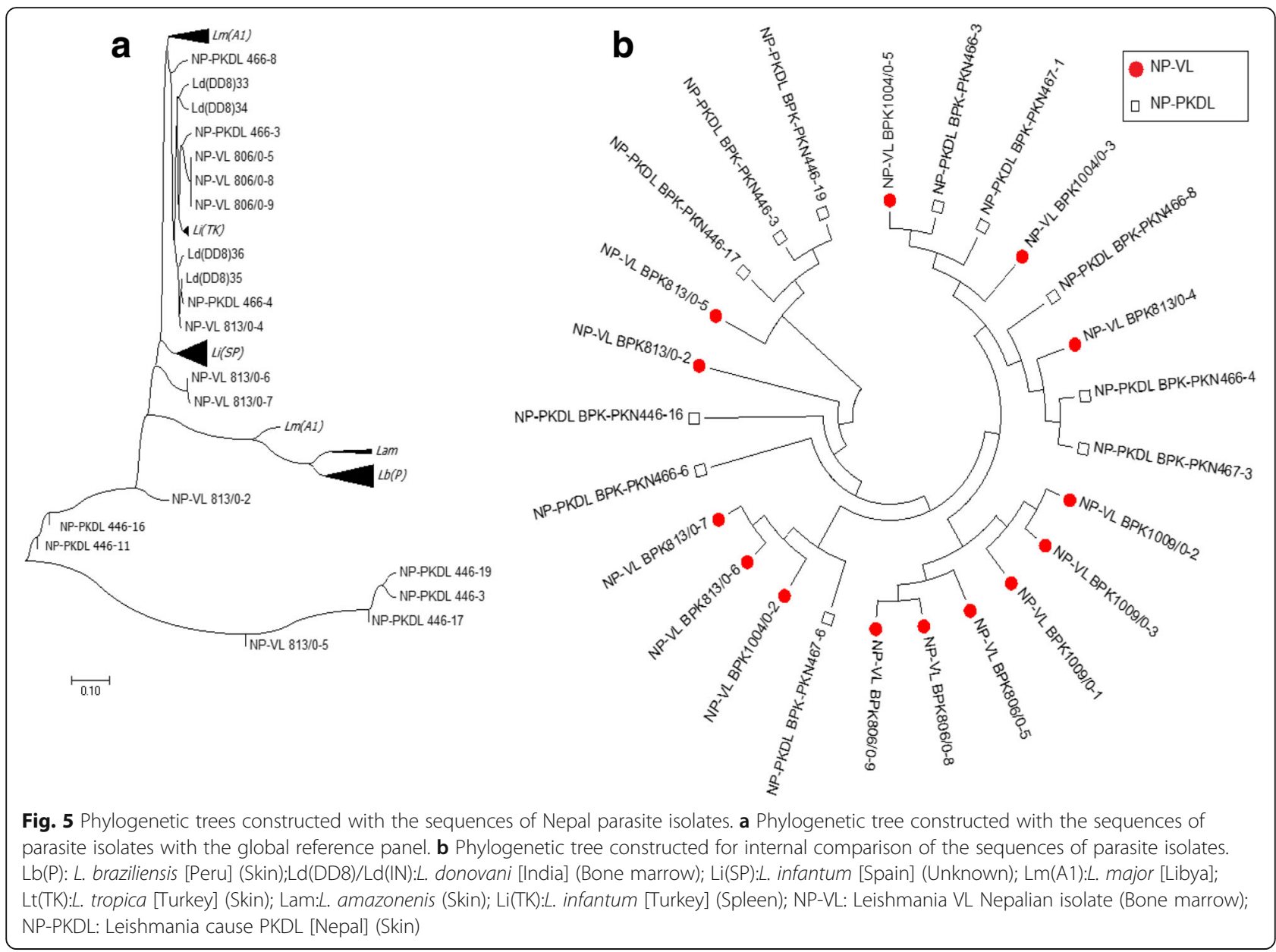

with $L$. infantum, a closely related subspecies within the $L$. donovani complex $[5,61]$. However, within the $L$. donovani group of sequences, the Sri Lankan parasites formed a distinct cluster, in agreement with previous observations made using different genotyping tools [8]. This may indicate the parasite's existence over a prolonged period within the country, though the clinical cases were recognized only recently [11]. Interestingly, the Sri Lankan parasites belonged to a group, which was well differentiated from other dermotropic Leishmania parasites viz., L. tropica, L. major, L. amazonensis and L. braziliensis indicating potential population isolation.

There were three distinct sub-clusters seen within the Sri Lankan group, comprising sequences from visceral leishmaniasis (VL) patients, cutaneous leishmaniasis patients (CL-S), and CL cases that showed poor response to the standard drug SSG (CL-DR). However, no specific clustering was observed in relation to their geographical origins within Sri Lanka. The phylogenetic differentiation within CL-S, CL-DR and $\mathrm{VL}$ may be due to the genetic mutations/variations associated with these three clinical groups (viz. VL, uncomplicated $\mathrm{CL}$ and $\mathrm{CL}$ with poor response to antimonial drugs, which is currently used as the first line of treatment in Sri Lanka) [66].

It is possible that multiple genetic strains of $L$. donovani exist within Sri Lanka, as reported from other geographic regions in the world [19, 31, 35]. Occasional reports on atypical cutaneous leishmaniasis reported in literature, indicate that more than one strain of L. donovani is likely to cause cutaneous disease [5, 6, 29]. $L$. donovani strains of the same genetic and/or geographical group are also known to result in different clinical outcomes [35]. This study with Sri Lankan isolates further affirms that there is sub-genetic diversity in L. donovani in the Indian subcontinent, which warrants further investigation on how that diversity translates into pathogenesis and its implications on patient management and treatment outcome.

Sri Lankan L. donovani parasites are likely to have evolved more recently as a novel group compared to other members of the genus, since the sequences from these isolates were found in the most peripheral branches of the phylogram. Given Sri Lanka's geographic position as an island close to India, the parasites may have been in circulation within the country long enough 
to adopt such independent genetic characteristics. However, it is unlikely that these parasites were introduced within the last 2-3 decades, when the disease became apparent. As suggested by past genetic studies, the $L$. donovani complex has originated 3-4 million years ago [31, 35]. Initial cases reported in Sri Lanka about 30 years ago were all imported cases from the Middle East and Africa $[67,68]$. Leishmania parasites are known to find new ecologies along with the immigration of people [55, $68,69]$. It is possible that the parasites may have been introduced to Sri Lanka by locals returning after employment overseas or by foreign immigrants $[5,68]$. Sri Lankan Leishmania parasites may have co-evolved with the ecological settings along with its vector and possible reservoir hosts. However, this remains mere speculation with the precise origin of the Sri Lankan L. donovani parasites being debatable and not addressed through the present study.

Use of the kDNA minicircle region can be used as a surrogate genotyping tool for the identification of species-specific sequence footprints among different species of Leishmania and for the identification of new Leishmania species or strains with relative ease and reasonable accuracy. Such tools can be cost-effective in resource limited settings and provide for rapid identification of parasite species. However, such data obtained are unlikely to provide accurate information on evolutionary history of the parasite, which in turn may require high resolution evaluation of the whole genome and sequence analysis of markers that are representative of the entire parasite genome.

\section{Conclusion}

For the first time this study reveals the extent of genetic diversity of $L$. donovani in Sri Lanka and a clear clustering nature of local parasites according to their antimonial sensitivity and tissue localization. Furthermore, the genetic differentiation between CL-DR and CL-S suggests a likely genetic basis for poor responsiveness to antimonial drugs and possible drug resistance. Overall, genetic variations associated with specific functional characteristics are likely to influence the disease phenotype, which is of clinical relevance and significance. Studies are underway to use whole genome sequence information with more detailed and higher resolution mapping, to investigate the parasite genetic variations associated with distinct clinical manifestations.

\section{Additional files}

Additional file 1: Multiple sequence alignment. Multiple sequence alignment of the Sri Lankan, Indian and Nepalese isolates along with the reference sequences using CLUSTAL 2.1 multiple sequence alignment. Dashes $(-)$ represent gaps introduced to optimize alignment. Asteriks $\left({ }^{*}\right)$ represent consensus nucleotides in the sequence. $\mathrm{Lb}(\mathrm{P}): \mathrm{L}$. braziliensis [Peru] (Skin);Ld(DD8)/Ld(IN):L. donovani [India] (Bone marrow); Li(SP):L. infantum [Spain] (Unknown); Lm(A1):L. major [Libya]; Lt(TK):L. tropica [Turkey] (Skin); Lam: L. amazonenis (Skin); Li(TK):L. infantum [Turkey] (Spleen); SL-VL (52-55): VL Sri Lankan isolate (Bone marrow); SL CLS:Leishmania CL Sri Lankan isolate (Skin); SL_CL-DR:Leishmania CL Sri Lankan that failed to respond to antimonial drugs (Skin); IN-VL:

L. donovani [India] (Bone marrow); IN-PKDL: Leishmania from post-kala azar dermal leishmaniasis (PKDL) [India] (Skin); NP-VL: Leishmania VL Nepalian isolate (Bone marrow); NP-PKDL:Leishmania cause PKDL [Nepal] (Skin). (DOCX 25 kb)

Additional file 2: The isolation by distance analysis showed the linear correlation between genetic diversity and geographic distance. Three populations were defined such as Sri Lanka, India and Nepal. However, this correlation was not statistically significant. (DOC $175 \mathrm{~kb}$ )

\section{Abbreviations}

CL: Cutaneous leishmaniasis; FBS: Fetal bovine serum; FST: Pair wise fixation index; gp63: Glycoprotein 63; Hd: Haplotype diversity; IL-SSG: Intra-lesional sodium stibogluconate; ITS: Internal transcribed spacer; kDNA: Kinetoplastid DNA; LPG: Lipophosphoglycan; MCL: Muco-cutaneous leishmaniasis; MSA: Multiple sequence alignment; Nd: Nucleotide diversity; PCR: Polymerase Chain Reaction; PKDL: Post kala-azar dermal leishmaniasis; SL-CL-

DR: Cutaneous leishmaniasis that showed poor response to antimony therapy in Sri Lanka; SL-CL-S: Uncomplicated cutaneous leishmaniasis in Sri Lanka; SL-VL: Visceral disease in Sri Lanka; VL: Visceral leishmaniasis

\section{Acknowledgements}

We acknowledge the Dermatologists in all study areas for assistance with patient care, Mr. Sudath Weerasinghe and Ms. Nirosha Pathirana at Faculty of Medicine, Colombo, Ms. Ginni Arora at IMM for technical assistance and Dr. G. Sreenivas and Dr. Ranadhir Dey for valuable comments on the manuscript. Dr. John Hobson at Food and Drug Administration, USA is also acknowledged for language editing.

\section{Funding}

Research reported in this publication was supported by University of Colombo grant AP/3/2011/CG/01 and the National Institute of Allergy And Infectious Diseases of the National Institutes of Health, USA under Award Number R01Al099602 and U01Al136033. The content is solely the responsibility of the authors and does not necessarily represent the official views of the National Institutes of Health.

\section{Availability of data and materials}

The datasets generated and/or analyzed during the current study are available in the [GenBank] repository (GenBank reference numbers KU201288-KU201312, KU 220245-KU220268) or are available from the corresponding author on request.

\section{Authors' contributions}

Conceived and designed the experiments-UK, NDK, HN, AS, SR, NRB, YS. Performed the experiments-UK, KA, THW, KR, MAB. Analyzed the data-UK, AS, HUP, DZ, GZ. Wrote the paper- UK, NDK, Read and approved the manuscriptall authors.

\section{Ethics approval and consent to participate}

Written informed consent was obtained from all individuals. Ethical approval for the study was granted by the Ethics Review Committee, Faculty of Medicine, University of Colombo (ERC-12-068).

\section{Consent for publication}

Not applicable.

\section{Competing interests}

The authors declare that they have no competing interests. None of the authors of this paper has a financial or personnel relationship with people or organizations that could inappropriately influence or bias the content of the paper. 


\section{Publisher's Note}

Springer Nature remains neutral with regard to jurisdictional claims in published maps and institutional affiliations.

\section{Author details}

'Department of Parasitology, Faculty of Medicine, University of Colombo, No. 25, Kynsey Road, Colombo 8, Sri Lanka. ${ }^{2} \mathrm{JH}$-Institute of Molecular Medicine, Jamia Hamdard, New Delhi, India. ${ }^{3}$ Department of Microbiology, B.P. Koirala Institute of Health Sciences, Dharan, Nepal. ${ }^{4}$ Department of Biology, University of South Dakota, Vermillion, SD, USA. ${ }^{5}$ University of California Irvine, College of Health Sciences, Irvine, CA, USA. ${ }^{6}$ Division of Emerging and Transfusion Transmitted Diseases, Food and Drug Administration, Bethesda, USA.

Received: 14 July 2017 Accepted: 5 December 2017 Published online: 22 December 2017

\section{References}

1. Alvar J, Vélez ID, Bern C, Herrero M, Desjeux P, Cano J, Jannin J, Boer M Den: Leishmaniasis worldwide and global estimates of its incidence. PLoS One 2012, 7:e35671.

2. Imamura $H$, Downing $T$, van den Broeck F, Sanders MJ, Rijal S, Sundar S, Mannaert A, Vanaerschot M, Berg M, de Muylder G, Dumetz F, Cuypers B, Maes I, Domagalska M, Decuypere S, Rai K, Uranw S, Bhattarai NR, Khanal B, Prajapati VK, Sharma S, Stark O, Schönian G, de Koning HP, Settimo L, Vanhollebeke B, Roy S, Ostyn B, Boelaert M, Maes L, et al.: Evolutionary genomics of epidemic visceral leishmaniasis in the Indian subcontinent. elife 2016, 5(MARCH2016):1-39.

3. WHO. Control of the leishmaniases. World Health Organ Tech Rep Ser. 2010:22-6.

4. Kuhls K, Alam MZ, Cupolillo E, Ferreira GEM, Mauricio IL, Oddone R, Feliciangeli MD, Wirth T, Miles MA, Schönian G. Comparative microsatellite typing of new world Leishmania infantum reveals low heterogeneity among populations and its recent old world origin. PLoS Negl Trop Dis. 2011;5:1-16.

5. Mauricio IL, Howard MK, Stothard JR, Miles MA. Genomic diversity in the Leishmania donovani complex. Parasitology. 1999:119(3):237-46.

6. Pratlongl F, Bastienl P, Perello R, Lamil P, Dedetl IP, France M. Human cutaneous leishmaniasis caused by Leishmania donovani sensu stricto in Yemen. Trans R Soc Trop Med Hyg. 1995;89:398-9.

7. Karunaweera ND, Pratlong F, Siriwardane HVYD, Ihalamulla RL, Dedet JP. Sri Lankan cutaneous leishmaniasis is caused by Leishmania donovani zymodeme MON-37. Trans R Soc Trop Med Hyg. 2003;97:380-1.

8. Siriwardena HVYD, Noyes HA, Beeching NJ, Chance ML, Karunaweera ND, Bates PA. Leishmania donovani and Cutaneous leishmaniasis, Sri Lanka. Emerg Infect Dis. 2007:13:3-5.

9. Thakur CP, Dedet JP, Narain S, Pratlong F. Leishmania species, drug unresponsiveness and visceral leishmaniasis in Bihar, India. Trans R Soc Trop Med Hyg. 2001;95:187-9.

10. Nawaratna SSK, Weilgama DJ, Wijekoon CJ, Dissanayake M, Rajapaksha K Cutaneous Leishmaniasis, Sri Lanka. Emerg Infect Dis. 2007;13:1-3.

11. Karunaweera ND. Leishmania donovani causing cutaneous leishmaniasis in Sri Lanka: a wolf in sheep's clothing? Trends Parasitol. 2009;25:458-63.

12. Epidemiology Unit [http://epid.gov.lk/web/]. Accessed 5 June 2016.

13. Rajapaksa US, Ihalamulla RL, Karunaweera ND. First report of mucosal tissue localisation of leishmaniasis in Sri Lanka. Ceylon Med J. 2005;50:90-1.

14. Rathnayake D, Ranawake RR, Sirimanna G, Siriwardhane Y, Karunaweera ND, De Silva R. Co-infection of mucosal leishmaniasis and extra pulmonary tuberculosis in a patient with inherent immune deficiency. Int J Dermatol. 2010;49:549-51.

15. Ranasinghe $S$, Zhang W-W, Wickremasinghe R, Abeygunasekera $P$, Chandrasekharan V, Athauda S, Mendis S, Hulangamuwa S, Matlashewski G, Pratlong F. Leishmania donovani zymodeme MON-37 isolated from an autochthonous visceral leishmaniasis patient in Sri Lanka. Pathog Glob Health. 2012;106:421-4

16. Refai FW, Madarasingha N, Fernandopulle R, Karunaweera ND. Nonresponsiveness to standard treatment in cutaneous leishmaniasis: a case series from Sri Lanka. Trop Parasitol. 2016;6:4-8.

17. McCall L-I, Zhang W-W, Matlashewski G. Determinants for the development of visceral leishmaniasis disease. PLoS Pathog. 2013:9:e1003053.

18. McCall L-I, Matlashewski G. Localization and induction of the A2 virulence factor in Leishmania: evidence that $A 2$ is a stress response protein. Mol Microbiol. 2010;77:518-30.
19. Zhang WW, Ramasamy G, McCall L-I, Haydock A, Ranasinghe S, Abeygunasekara P, Sirimanna G, Wickremasinghe R, Myler P, Matlashewski $G$. Genetic analysis of Leishmania donovani tropism using a naturally attenuated Cutaneous strain. PLoS Pathog. 2014;10:e1004244.

20. Zhang WW, Matlashewski G. Characterization of the A2-A2rel gene cluster in Leishmania donovani: involvement of A2 in visceralization during infection. Mol Microbiol. 2001;39:935-48.

21. Zhang W-W. Comparison of the A2 gene locus in Leishmania donovani and Leishmania major and its control over Cutaneous infection. J Biol Chem. 2003;278:35508-15.

22. Beverley SM, Turco SJ. Lipophosphoglycan (LPG) and the identification of virulence genes in Leishmania. Trends Microbiol. 1998;6:35-40.

23. Späth GF, Epstein L, Leader B, Singer SM, Avila HA, Turco SJ, Beverley SM. Lipophosphoglycan is a virulence factor distinct from related glycoconjugates in the protozoan parasite Leishmania major. Proc Natl Acad Sci U S A. 2000;97:9258-63.

24. Turco SJ, Späth GF, Beverley SM. Is lipophosphoglycan a virulence factor? A surprising diversity between Leishmania species. Trends Parasitol. 2001;17:223-6.

25. Zhang K, Showalter M, Revollo JEA. Sphingolipids are essential for differentiation but not growth in Leishmania. EMBO J. 2003;22:6016-26.

26. Chen DQ, Kolli BK, Yadava N, Lu HG, Gilman-Sachs A, Peterson DA, Chang KP. Episomal expression of specific sense and antisense mRNAs in Leishmania amazonensis: modulation of gp63 level in promastigotes and their infection of macrophages in vitro. Infect Immun. 2000;68:80-6.

27. Downing $T$, Imamura $H$, Decuypere $S$, Clark TG, Coombs GH, Cotton JA, Hilley JD, de Doncker S, Maes I, Mottram JC, Quail MA, Rijal S, Sanders M, Schonian G, Stark O, Sundar S, Vanaerschot M, Hertz-Fowler C, Dujardin J-C, Berriman $\mathrm{M}$. Whole genome sequencing of multiple Leishmania donovani clinical isolates provides insights into population structure and mechanisms of drug resistance. Genome Res. 2011:21:2143-56.

28. Morales MA, Chicharro C, Ares M, Cañavate C, Barker DC, Alvar J. Molecular tracking of infections by Leishmania infantum. Trans R Soc Trop Med Hyg. 2001;95:104-7.

29. Peacock CS, Seeger K, Harris D, Murphy L, Ruiz JC, Quail MA, Peters N, Adlem E, Tivey A, Aslett M, Kerhornou A, Ivens A, Fraser A, Rajandream M-A, Carver T, Norbertczak H, Chillingworth T, Hance Z, Jagels K, Moule $\mathrm{S}$, Ormond D, Rutter S, Squares R, Whitehead S, Rabbinowitsch E, Arrowsmith C, White B, Thurston S, Bringaud F, Baldauf SL, et al. Comparative genomic analysis of three Leishmania species that cause diverse human disease. Nat Genet. 2007;39:839-47.

30. Rogers WO, Wirth DF. Kinetoplast DNA minicircles: regions of extensive sequence divergence. Proc Natl Acad Sci U S A. 1987;84:565-9.

31. Zemanová E, Jirků M, Mauricio IL, Miles MA, Lukes J. Genetic polymorphism within the Leishmania donovani complex: correlation with geographic origin. Am J Trop Med Hyg. 2004;70:613-7.

32. Selvapandiyan A, Duncan R, Mendez J, Kumar R, Salotra P, Cardo LJ, Nakhasi HL. A Leishmania minicircle DNA footprint assay for sensitive detection and rapid speciation of clinical isolates. Transfusion. 2008:48:1787-98.

33. Singh N, Curran MD, Middleton D, Rastogi AK. Characterization of kinetoplast DNA minicircles of an Indian isolate of Leishmania donovani. Acta Trop. 1999;73:313-9.

34. Singh N, Curran MD, Rastogil AK, Middleton D, Sundar S. Diagnostic PCR with Leishmania donovani specificity using sequences from the variable region of kinetoplast minicircle DNA. Trop Med Int Heal. 1999;4:448-53.

35. Lukes J, Mauricio IL, Schönian G, Dujardin J-C, Soteriadou K, Dedet J-P, Kuhls K, Tintaya KWQ, Jirků M, Chocholová E, Haralambous C, Pratlong F, Oborník M, Horák A, Ayala FJ, Miles MA. Evolutionary and geographical history of the Leishmania donovani complex with a revision of current taxonomy. Proc Natl Acad Sci U S A. 2007;104:9375-80.

36. Liu B, Liu Y, Motyka SA, Agbo EEC, Englund PT. Fellowship of the rings: the replication of kinetoplast DNA. Trends Parasitol. 2005;21:363-9.

37. Davies CR, Kaye P, Croft SL, Sundar S. Leishmaniasis: new approaches to disease control. BMJ. 2003;326:377-82.

38. Reithinger R, Dujardin JC. Molecular diagnosis of leishmaniasis: Current status and future applications. J Clin Microbiol. 2007:45(1):21-5.

39. Safi N. Evaluation of thermotherapy for the treatment of cutaneous Leishmaniasis in Kabul, Afghanistan: a randomized controlled trial. Int J Infect Dis. 2012;16(March):e174

40. Silva SY, Rueda LC, López M, Vélez ID, Rueda-Clausen CF, Smith DJ, Muñoz G, Mosquera H, Silva FA, Buitrago A, Díaz H, López-Jaramillo P. Double blind, randomized controlled trial, to evaluate the effectiveness of a controlled 
nitric oxide releasing patch versus meglumine antimoniate in the treatment of cutaneous leishmaniasis [NCT00317629]. Trials. 2006;7:14.

41. Batista LFDS, Segatto M, Guedes CES, Sousa RS, Rodrigues CAT, JCM B, Silva JS, Santos SO, Larangeira D, Macedo AM, Schriefer A, PST V. An assessment of the genetic diversity of Leishmania infantum isolates from infected dogs in Brazil. Am J Trop Med Hyg. 2012;86:799-806.

42. Ranasinghe S, Wickremasinghe R, Hulangamuwa S, Sirimanna G, Opathella $\mathrm{N}$, Maingon RDC, Chandrasekharan V. Polymerase chain reaction detection of Leishmania DNA in skin biopsy samples in Sri Lanka where the causative agent of cutaneous leishmaniasis is Leishmania donovani. Mem Inst Oswaldo Cruz. 2015;110:1017-23.

43. Tsokana CN, Athanasiou LV, Valiakos G, Spyrou V, Manolakou K, Billinis C. Molecular Diagnosis of Leishmaniasis, Species Identification and Phylogenetic Analysis, Leishmaniasis - Trends in Epidemiology, Diagnosis and Treatment, Dr. David Claborn (Ed.), Chapter 8; 2014. p. 161-193.

44. Thompson JD, Higgins DG, Gibson TJ. CLUSTAL W: improving the sensitivity of progressive multiple sequence alignment through sequence weighting, position-specific gap penalties and weight matrix choice. Nucleic Acids Res. 1994:22:4673-80.

45. Larkin MA, Blackshields G, Brown NP, Chenna R, Mcgettigan PA, McWilliam H, Valentin F, Wallace IM, Wilm A, Lopez R, Thompson JD, Gibson TJ, Higgins DG. Clustal W and Clustal X version 2.0. Bioinformatics. 2007;23:2947-8.

46. Librado P, Rozas J. DnaSP v5: a software for comprehensive analysis of DNA polymorphism data. Bioinformatics. 2009;25:1451-2.

47. Tajima F. Statistical method for testing the neutral mutation hypothesis by DNA polymorphism. Genetics. 1989;123:585-95.

48. Fu YX. Statistical tests of neutrality of mutations against population growth, hitchhiking and background selection. Genetics. 1997;147:915-25.

49. Ashfaq M, Hebert PDN, Mirza MS, Khan AM, Mansoor S, Shah GS, Zafar Y. DNA barcoding of Bemisia Tabaci Complex (Hemiptera: Aleyrodidae) reveals southerly expansion of the dominant whitefly species on cotton in Pakistan. PLoS One. 2014;9:1-14.

50. Goodall-Copestake WP, Tarling GA, Murphy EJ. On the comparison of population-level estimates of haplotype and nucleotide diversity: a case study using the gene cox1 in animals. Heredity (Edinb). 2012;109:50-6.

51. Excoffier L, Laval G, Schneider S. Arlequin (version 3.0): an integrated software package for population genetics data analysis. Evol Bioinformatics Online. 2005;1:47-50

52. Wright S. Variability Within and Among Natural Populations. Evolution and the Genetics of Populations, Volume 4. University of Chicago Press, USA; 1978.

53. Jenson JL, Bohonak AJ, Kelley ST. Isolation by distance, web service.6(13). BMC Genet. 2005;3:23. http://www.bio.sdsu.edu/pub/andy/IBD.html.

54. Tamura K, Stecher G, Peterson D, Filipski A, Kumar S. MEGA6: molecular evolutionary genetics analysis version 6.0. Mol Biol Evol. 2013;30:2725-9.

55. Ramírez JD, Hernández C, León CM, Ayala MS, Flórez C, González C. Taxonomy, diversity, temporal and geographical distribution of Cutaneous Leishmaniasis in Colombia: A retrospective study. Scientific Reports. 2016;6(1).

56. Bhattarai NR, Dujardin JC, Rijal S, De Doncker S, Boelaert M, Van der Auwera G. Development and evaluation of different PCR-based typing methods for discrimination of Leishmania donovani isolates from Nepal. Parasitology. 2010;137:947-57.

57. Pritchard JK, Stephens M, Donnelly P. Inference of population structure using multilocus genotype data. Genetics. 2000;155:945-59.

58. Alonso DP, Costa DL, Mendonça IL, De Henrique C, Costa N, Eduardo P, Ribolla M. Short report: heterogeneity of Leishmania infantum chagasi Kinetoplast DNA in Teresina (Brazil). Am J Trop Med Hyg. 2010;82:819-21.

59. de Oliveira JP, Fernandes F, Cruz AK, Trombela V, Monteiro E, Camargo AA, Barral A, de Oliveira Cl. Genetic diversity of Leishmania amazonensis strains isolated in northeastern Brazil as revealed by DNA sequencing, PCR-based analyses and molecular karyotyping. Kinetoplastid Biol Dis. 2007;6(LCl):5.

60. Seblova V, Myskova J, Hlavacova J, Votypka J, Antoniou M, Volf P. Natural hybrid of Leishmania infantum/L. donovani: development in Phlebotomus tobbi, P. perniciosus and Lutzomyia longipalpis and comparison with nonhybrid strains differing in tissue tropism. Parasit Vectors. 2015;8:605.

61. Segatto M, Ribeiro LS, Costa DL, Costa CHN, de Oliveira MR, Carvalho SFG, Macedo AM, Valadares HMS, Dietze R, de Brito CFA, Lemos EM. Genetic diversity of Leishmania infantum field populations from Brazil. Mem Inst Oswaldo Cruz. 2012;107:39-47.

62. Peters NC, Egen JG, Secundino N, Debrabant A, Kimblin N, Kamhawi S, Lawyer P, Fay MP, Germain RN, Sacks D. Demonstration of genetic exchange during cyclical development of Leishmania in the sand fly vector. Science (80-). 2009;324:265-8.

63. Gajapathy K, Jude PJ, Surendran SN. Morphometric and meristic characterization of Phlebotomus argentipes species complex in northern Sri Lanka: evidence for the presence of potential leishmaniasis vectors in the country. Trop Biomed. 2011;28:259-68.

64. Ozbel Y, Sanjoba C, Alten B, Asada M, Depaquit J, Matsumoto Y, Demir S, RRMLR S, RPVJ R, Matsumoto Y. Distribution and ecological aspects of sand fly (Diptera: Psychodidae) species in Sri Lanka. J Vector Ecol. 2011;36 Suppl 1(Karunaweera):S77-86.

65. Karunaweera,N.D., Siriwardana HVYD, Karunanayake P.: Management of leishmaniasis. Sri Lanka Prescr 2013, 21:1-5.

66. Wijesundera MS. Cutaneous leishmaniasis: an emerging health risk in Sri Lanka. Ceylon Med J. 2001;46:151-2.

67. Naotunne TD, Rajakulendran S, Abeyewickreme W, Kulasiri CD, Perera J, Premaratne U. Cutaneous leishmaniasis in Sri Lanka: an imported disease linked to the middle-east and African employment boom. Trop Geogr Med. 1990;42:72-4.

68. Dissanayake AS: Parasitic zoonoses with special reference to Sri Lanka. In In: Elizabeth U canning Ed. parasitological topics. Society of Protozoologists, Kansas USA: Allen Press Inc., 1981: 78-85.

69. Sang DK, Njeru WK, Ashford RW. A possible animal reservoir for Leishmania tropica s.L. in Kenya. Ann Trop Med Parasitol. 1992;86:311-2.

\section{Submit your next manuscript to BioMed Central and we will help you at every step:}

- We accept pre-submission inquiries

- Our selector tool helps you to find the most relevant journal

- We provide round the clock customer support

- Convenient online submission

- Thorough peer review

- Inclusion in PubMed and all major indexing services

- Maximum visibility for your research

Submit your manuscript at www.biomedcentral.com/submit
(O) BioMed Central 